\title{
Estratégias de leitura - estado da arte
}

\section{Reading strategies - state of art}

\author{
Sílvia de Fátima Pilegi Rodrigues*
}

\begin{abstract}
RESUMO
O propósito deste texto é apresentar um balanço da pesquisa sobre "estratégias de leitura" tomando como referência as publicações constantes em três bases: teses e dissertações, anais de eventos nacionais da área e artigos em periódicos. Tomou-se como ponto de partida a presença da expressão "estratégia de leitura" no título da publicação. Após esse registro, procedeu-se à leitura do resumo para analisar: a fundamentação teórica e a confluência (ou não) entre os autores, a metodologia empregada, dentre outros elementos. Palavras-chave: Estratégias de Leitura. Leitura. Alfabetização.
\end{abstract}

\begin{abstract}
The purpose of this text is to present a research on reading strategies balance, taking as reference the publications in three bases: theses and dissertations, congress proceedings of national events of the area and articles in periodicals. The starting point was the presence of the expression "reading strategy" in the publication's title. After this registration, the abstract was read to analyze: the theoretical basis and the confluence (or not) between the authors, the methodology employed, among other elements.
\end{abstract}

Keywords: Reading Strategies. Reading. Literacy.

* Universidade Federal de Mato Grosso. Campus Universitário de Rondonópolis. Programa de Pós-Graduação em Educação. Grupo de Pesquisa ALFALE. Rondonópolis, Mato Grosso, Brasil. E-mail: silviapilegi@gmail.com. https://orcid.org/0000-0002-0109-4593. 


\section{Introdução}

O tema "estratégia de leitura" vem despontando no foco de interesse de profissionais da Educação e demais pesquisadores com vistas à formação de leitores proficientes e autônomos e, nessa direção, muitos estudos, principalmente sob a influência de autores como Solé, Kato Kleiman, Koch e Elias, Girotto e Souza, têm sido realizados no Brasil.

O propósito deste texto é apresentar um balanço de uma pesquisa do tipo estado da arte sobre "estratégias de leitura", tomando como referência publicações constantes em três bases: teses e dissertações, anais de eventos nacionais da área e artigos em periódicos.

O ponto de partida para a coleta de dados foi a presença da expressão "estratégia de leitura" no título da publicação, e, após esse registro, procedeu-se à leitura do resumo para analisar: a fundamentação teórica e a confluência (ou não) entre os autores, a metodologia empregada, dentre outros elementos. Para tanto, foi feito levantamento de informações nos seguintes portais:

a) as teses e dissertações foram consultadas a partir do portal da Biblioteca Digital Brasileira de Teses e Dissertações (BDTD), no endereço < http://bdtd. ibict.br>, com a delimitação temporal de 2000 a 2017;

b) os textos de comunicações orais de eventos foram consultados em anais das reuniões da Associação Nacional de Pós-Graduação e Pesquisa em Educação (Anped), no endereço <http://www.anped.org.br/news/anais-das-reunioes-nacionais-da-anped-issn-2447-2808>; o GT10 “Alfabetização, Leitura e Escrita" foi o foco de análise, e os anais do Congresso de Leitura do Brasil (Cole), disponíveis em <http://alb.org.br/anais-cole/>. Como a temática central do Cole é leitura, e devido à sua abrangência, optou-se por delimitar a pesquisa analisando as publicações no "Seminário sobre Letramento e Alfabetização" para poder gerar dados que pudessem confluir com o GT10 da Anped. A partir do $18^{\circ}$ Congresso, a organização do evento foi alterada, não sendo mais por seminários, mas sim por linhas temáticas, e os textos foram publicados em cadernos de resumos e revistas. Portanto a coleta de dados referentes ao $18^{\circ}$ até o $20^{\circ}$ Cole deu-se a partir dos cadernos de resumos e revistas;

c) os artigos científicos foram coletados no portal Scientific Electronic Library Online (SciELO), no endereço <http://www.scielo.br/>, que disponibiliza acesso aberto a periódicos e facilita a navegação e pesquisa em conteúdos de coleções, periódicos, fascículos e artigos. A delimitação temporal também foi de 2000 a 2017.

Como explicitam Romanowski e Ens, 
Os estudos realizados a partir de uma sistematização de dados, denominada "estado da arte", recebem esta denominação quando abrangem toda uma área do conhecimento, nos diferentes aspectos que geraram produções. Por exemplo: para realizar um "estado da arte" sobre "Formação de Professores no Brasil" não basta apenas estudar os resumos de dissertações e teses, são necessários estudos sobre as produções em congressos na área, estudos sobre as publicações em periódicos da área. $\mathrm{O}$ estudo que aborda apenas um setor das publicações sobre o tema estudado vem sendo denominado de "estado do conhecimento" (2006, p. 39-40 - grifos do original).

No presente estudo, os resumos são o ponto de partida para o levantamento de dados, pois também foram acessados os textos na íntegra para a coleta de informações pertinentes a esta pesquisa, embora não seja ignorada a argumentação de Ferreira (2002, p. 264) ao enfatizar que

[...] há grande heterogeneidade entre eles (os resumos) explicável não só pelas representações diferentes que cada autor do resumo tem deste gênero discursivo, mas também por diferenças resultantes do confronto dessas representações com algumas características peculiares da situação comunicacional $[\ldots]$

Nesse sentido, é importante ressaltar que muitos resumos das teses e dissertações não explicitavam elementos como: tema, problema, objetivo, metodologia dentre outros atinentes ao gênero para o texto acadêmico, o que demandou a leitura na íntegra dos materiais.

Ainda que não se tenha a pretensão de esgotar o assunto e reconhecendo que todo estudo tem limites, mas também abre a possibilidade para que muitos outros derivem dele, o que se propõe aqui é contribuir com um balanço da pesquisa sobre "estratégias de leitura", tema esse que, como os dados demonstrarão, vem despontando no foco de interesse de muitos estudiosos.

Estados da arte podem significar uma contribuição importante na constituição do campo teórico de uma área de conhecimento, pois procuram identificar os aportes significativos da construção da teoria e prática pedagógica,apontar as restrições sobre o campo em que se move a pesquisa, as suas lacunas de disseminação, identificar experiências inovadoras 
investigadas que apontem alternativas de solução para os problemas da prática e reconhecer as contribuições da pesquisa na constituição de propostas na área focalizada (ROMANOWSKI; ENS, 2006, p. 39).

No processo de levantamento e análise dos dados, o critério foi a presença do descritor "estratégia(s) de leitura" no título. Assim sendo, embora tenham sido identificados textos contendo essas palavras apenas no conteúdo, eles não foram tomados como material de análise nesta pesquisa, tendo em vista a delimitação inicial; também não foram pesquisados textos nos quais as palavras "estratégia" e "leitura" não formassem uma locução.

\section{Teses e dissertações - a produção a partir do descritor "estratégia de leitura"}

Na coleta inicial de dados no banco da Biblioteca Digital Brasileira de Teses e Dissertações (BDTD), ao utilizar o descritor "estratégia de leitura" no título, obteve-se 88 trabalhos, sendo 76 dissertações e 19 teses. Não houve alteração numérica ao empregar os termos no plural. A seguir, serão detalhados e analisados os dados obtidos, a começar pelas teses de doutorado e, na sequência, as dissertações de mestrado, ambas com a delimitação temporal de 2000 a 2017 como ano de defesa.

\section{Sobre as teses com o descritor "estratégia de leitura"}

Ao consultar os títulos das teses, verificou-se que dois deles estavam repetidos; portanto ficaram 17 para a análise preliminar. Desse conjunto, 10 deles, apesar de conterem as palavras "leitura" e "estratégia" no título, não remetiam ao foco desta pesquisa, pois voltavam-se para questões como: estratégia de aprendizagem, de ensino, de trabalho, tático-técnicas e outras. As sete teses pertinentes ao objetivo deste estudo eram: 
QUADRO 1 - TESES COM O DESCRITOR “ESTRATÉGIA DE LEITURA” NOS TÍTULOS

\begin{tabular}{|l|l|c|c|}
\hline \multicolumn{1}{|c|}{ Título } & \multicolumn{1}{|c|}{ Autor } & \multicolumn{1}{c|}{ IES } & Ano \\
\hline $\begin{array}{l}\text { Estratégias de leitura na educação química e na } \\
\text { formação docente: necessidades e contribuições de um } \\
\text { planejamento crítico }\end{array}$ & $\begin{array}{l}\text { Wilmo Ernesto } \\
\text { Francisco Junior }\end{array}$ & UNESP & 2011 \\
\hline $\begin{array}{l}\text { Se(r) um leitor em um ambiente virtual e } \\
\text { aprendizagem: a utilização do insólito como estratégia } \\
\text { de leitura e escrita no ensino superior }\end{array}$ & $\begin{array}{l}\text { Carmem Lúcia } \\
\text { Quintana Pinto }\end{array}$ & UERJ & 2013 \\
\hline Estratégias de leitura e o ensino do ato de ler & $\begin{array}{l}\text { Silvana Paulina de } \\
\text { Souza }\end{array}$ & UNESP & 2014 \\
\hline $\begin{array}{l}\text { As estratégias de leitura sem e com o uso do Google } \\
\text { tradutor }\end{array}$ & $\begin{array}{l}\text { Adriana Riess } \\
\text { Karnal }\end{array}$ & $\begin{array}{c}\text { PUC- } \\
\text { RS }\end{array}$ & 2015 \\
\hline $\begin{array}{l}\text { Andersen e o ensino de estratégias de leitura: relações } \\
\text { entre leitores e textos }\end{array}$ & $\begin{array}{l}\text { Vania Kelen } \\
\text { BelãoVagula }\end{array}$ & UNESP & 2016 \\
\hline $\begin{array}{l}\text { Ler e jogar ou jogar e ler?: estratégias de leitura } \\
\text { empregadas por estudantes do 5 } \text { ano do ensino } \\
\text { fundamental ao jogar no click jogos }\end{array}$ & $\begin{array}{l}\text { Adriana Ferreira } \\
\text { Boeira }\end{array}$ & UCS & 2016 \\
\hline $\begin{array}{l}\text { Sequência didática e estratégias de leitura na } \\
\text { aprendizagem de produção de texto }\end{array}$ & $\begin{array}{l}\text { Gislene Aparecida } \\
\text { da Silva Barbosa }\end{array}$ & UNESP & 2017 \\
\hline
\end{tabular}

FONTE: elaborado pela autora a partir de dados coletados na BDTD (http://bdtd.ibict.br).

Como pode ser observado no Quadro 1, a Universidade Estadual Paulista (Unesp) apresentou maior número de teses na temática, com quatro registros. Outro dado relevante é que não foram localizadas teses anteriores a 2011, dentro dos parâmetros desta pesquisa. Quanto à região dos trabalhos, cinco eram de instituições de ensino superior (IES) da região Sudeste (Unesp e Universidade do Estado do Rio de Janeiro - Uerj) e duas do Sul do país (PUC-RS e Universidade de Caxias do Sul - UCS).

\section{QUADRO 2 - PRINCIPAIS OBRAS QUE FUNDAMENTAM AS DISCUSSÕES SOBRE "ESTRATÉGIAS DE LEITURA" NAS TESES}

\begin{tabular}{|l|c|}
\hline \multicolumn{1}{|c|}{ Autor/obra } & Freq. \\
\hline KLEIMAN, Angela. Oficina de leitura: teoria e prática & 04 \\
\hline SOLÉ, Isabel. Estratégias de leitura & 04 \\
\hline $\begin{array}{l}\text { HARVEY, Stephanie; GOUDVIS, Anne. Strategies that work: teaching comprehension } \\
\text { for understanding and engagement }\end{array}$ & 03 \\
\hline SOUZA, Renata Junqueira (Org.). Ler e compreender: estratégias de leitura & 02 \\
\hline OWOCKI, Gretchen. Comprehension - Strategic. Instruction for K-3 Students & 02 \\
\hline $\begin{array}{l}\text { SANTOS, Ana Maria Martins da Costa; Souza, Renata Junqueira de. Andersen e as } \\
\text { estratégias de leitura: atividades práticas no cotidiano escolar }\end{array}$ & 02 \\
\hline KLEIMAN, Angela. Leitura: ensino e pesquisa & 02 \\
\hline
\end{tabular}

FONTE: Elaborado pela autora a partir de dados coletados na BDTD (http://bdtd.ibict.br). 
As sete teses analisadas apresentaram conceituações de "estratégias de leitura" que, de modo geral, foram definidas como procedimentos conscientes (metacognitivos) dos quais o leitor se vale no ato da leitura para, de modo intencional, construir sentido.

Dentre as teses analisadas, verifica-se a predominância das obras de Angela Kleiman, com Oficina de leitura: teoria e prática e Leitura: ensino e pesquisa; e de Isabel Solé, com Estratégias de leitura (Quadro 2).

A obra Oficina de leitura: teoria e prática foi editada pela primeira vez em 1992 e nela se encontra a seguinte definição de "estratégias de leitura":

Quando falamos de ESTRATÉGIAS DE LEITURA, estamos falando de operações regulares para abordar o texto. Essas estratégias podem ser inferidas a partir da compreensão do texto, que por sua vez é inferida a partir do comportamento verbal e não verbal do leitor, isto é, do tipo de respostas que ele dá a perguntas sobre o texto, dos resumos que ele faz, de suas paráfrases, como também da maneira com que ele manipula o objeto: se sublinha, se apenas folheia sem se deter em parte alguma, se passa os olhos rapidamente e espera a próxima atividade começar, se relê (KLEIMAN, 2002, p. 49 - grifos do original).

Esse trecho da obra de Kleiman foi encontrado em várias teses e dissertações analisadas, tanto em forma de paráfrase quanto citação direta, geralmente em diálogo com o livro de Solé, a partir do seguinte trecho: “[...] procedimentos de caráter elevado, que envolvem a presença de objetivos a serem realizados, o planejamento das ações que desencadeiam para atingi-los, assim como sua avaliação e possível mudança.” (SOLÉ, 2012, p. 70).

Quanto às metodologias de pesquisa empregadas nas teses, foram nomeadas diretamente nos materiais analisados as seguintes: investigação-ação, metodologia think aloud protocols, experimento formativo, estudo de caso, análise de conteúdo, e duas teses indicaram a pesquisa-ação. Todas se identificaram com pesquisa de abordagem qualitativa.

\section{Sobre as dissertações com o descritor "estratégia de leitura"}

Empregando os mesmos critérios que os utilizados no levantamento de dados sobre teses na BDTD, obteve-se como resultado 76 dissertações. Contudo 
verificou-se que, desse total, sete estavam repetidas; consequentemente, ficaram 69 para a análise preliminar. Desse conjunto, em 36 delas, apesar de conterem as palavras leitura e estratégia nos títulos, não remetiam ao foco deste estudo, abordavam temas como: estratégia de aprendizagem, de ensino, pedagógica, familiar, de gestão e outras, ou não formavam a locução pesquisada. As 33 dissertações pertinentes não poderão ser listadas na íntegra aqui devido às restrições que se colocam para o artigo, mas os quadros ( 3 e 4 ) aqui constantes poderão dar uma dimensão da produção e tematização das dissertações. Eles não foram elaborados a partir da contagem feita automaticamente por $<\mathrm{http}$ :// bdtd.ibict.br>, pois o programa não exclui documentos com duplicidade, nem responderia com a devida precisão aos propósitos desta pesquisa.

QUADRO 3 - QUANTITATIVO DE DISSERTAÇÕES POR IES (2000-2017)

\begin{tabular}{|c|c|c|c|}
\hline Região & IES & Quant. & Subtotal \\
\hline \multirow{3}{*}{ Nordeste } & UFPB & 04 & \\
& UFPE & 03 & \multirow{2}{*}{09} \\
\cline { 2 - 3 } & UCAP & 02 & \\
Sudeste & PUC-SP & 06 & \multirow{2}{*}{09} \\
\hline Norte & UNESP & 03 & \\
\hline & UFPA & 03 & 03 \\
\hline & IES com 01 dissertação & 12 & 12 \\
\hline & Total de dissertações & 33 & 33 \\
\hline
\end{tabular}

FONTE: Elaborado pela autora a partir de dados coletados na BDTD (http://bdtd.ibict.br).

As IES com duas ou mais dissertações com o descritor "estratégia de leitura" (2000-2017) concentram-se nas regiões Nordeste e Sudeste, com nove trabalhos cada uma, e a Norte, representada pela Universidade Federal do Pará, com três dissertações. A Pontifícia Universidade Católica de São Paulo apresentou o maior número de dissertações defendidas, dentro dos parâmetros desta pesquisa, com um total de seis trabalhos. 
QUADRO 4 - PRINCIPAIS OBRAS QUE FUNDAMENTAM AS DISCUSSÕES SOBRE "ESTRATÉGIAS DE LEITURA” NAS DISSERTAÇÕES

\begin{tabular}{|l|c|}
\hline \multicolumn{1}{|c|}{ Autor/obra } & Freq. \\
\hline SOLÉ, Isabel. Estratégias de Leitura & 29 \\
\hline KOCH, Ingedore; ELIAS, Vanda M. Ler e Compreender: os sentidos do texto & 19 \\
\hline KLEIMAN, Angela. Texto e Leitor. Aspectos Cognitivos da Leitura & 18 \\
\hline KATO, Mary. O Aprendizado da Leitura & 15 \\
\hline KLEIMAN, Angela. Oficina de leitura: teoria e prática & 15 \\
\hline SMITH, Frank. Leitura Significativa & 08 \\
\hline $\begin{array}{l}\text { SMITH, Frank. Compreendendo a leitura: uma análise psicolinguística da leitura e do } \\
\text { aprender a ler }\end{array}$ & 06 \\
\hline $\begin{array}{l}\text { SERRA, Joan; OLLER, Carles. Estratégias de leitura e compreensão do texto no } \\
\text { ensino fundamental e médio }\end{array}$ & 05 \\
\hline KLEIMAN, Angela. Leitura: Ensino e Pesquisa & 05 \\
\hline VAN DIJK, TeunAdrianus. Cognição, Discurso e Interação & 04 \\
\hline LEFFA, Vilson J. Aspectos da leitura: uma perspectiva psicolinguística & 04 \\
\hline DELL'ISOLA, Regina Lucia Peret. Leitura: inferências e contexto sociocultural & 03 \\
\hline SOUZA, Silvana Ferreira de. Estratégias de leitura para a formação da criança leitora & 03 \\
\hline ROJO, Roxane. Letramentos múltiplos, escola e inclusão social & 03 \\
\hline $\begin{array}{l}\text { GIROTTO, Cyntia Graziella Guizelim Simões; SOUZA, Renata Junqueira de. } \\
\text { Estratégias de leitura: para ensinar alunos a compreender o que leem }\end{array}$ & 03 \\
\hline FOLTZ, Peter W. Comprehension, coherence, and strategies in hypertext and linear text & 02 \\
\hline KOCH, Ingedore. O texto e a construção dos sentidos & 02 \\
\hline $\begin{array}{l}\text { HARVEY, Stephanie; GOUDVIS, Anne. Strategies that work: teaching } \\
\text { comprehension for understanding and engagement }\end{array}$ & 02 \\
\hline GOODMAN, Kenneth S. Reading: A psycholinguistic guessing game & 02 \\
\hline $\begin{array}{l}\text { KOPKE FILHO, Henrique. Repertório de estratégias de compreensão da leitura e } \\
\text { conhecimento metacognitivo de professores de Língua Portuguesa }\end{array}$ & 02 \\
\hline KOCH, Ingedore. Desvendando os segredos do texto & 02 \\
\hline
\end{tabular}

FONTE: Elaborado pela autora a partir de dados coletados na BDTD (http://bdtd.ibict.br).

Considerando a diversidade de obras e os limites deste artigo, a atenção voltar-se-á para as cinco primeiras, sendo que a de Solé, já mencionada neste texto, constou em 29 das 33 dissertações, o que corresponde a $87,87 \%$ dos trabalhos tendo Estratégias de leitura na constituição do seu referencial teórico.

A obra de Ingedore Koch e Vanda Elias, Ler e Compreender: os sentidos do texto (2007), constou em 19 dissertações, principalmente no desenvolvimento ou observação e análise de práticas pedagógicas com a utilização de estratégias para a reflexão, compreensão e interação entre leitor, autor e texto. Duas obras de Angela Kleiman formaram o referencial das dissertações analisadas, sendo que Texto e Leitor. Aspectos Cognitivos da Leitura constou na bibliografia de 18 delas e Oficina de leitura: teoria e prática, em 15. Mary Kato com O Aprendizado da Leitura também constou em 15 dissertações. Em especial as discussões desenvolvidas no capítulo 6 da referida obra - "Estratégia em interpretação 
de sentenças e compreensão de textos" (KATO, 1995, p. 79-109) - aparecem nas obras analisadas para subsidiar a fundamentação teórica, a proposição de atividades e a observação da prática docente e dos demais sujeitos envolvidos em suas pesquisas.

No Quadro 5 a seguir constam as metodologias empregadas nas 33 dissertações.

QUADRO 5 - METODOLOGIAS DE PESQUISA EMPREGADAS NAS DISSERTAÇÕES

\begin{tabular}{|l|c|}
\hline \multicolumn{1}{|c|}{ Metodologia de pesquisa } & Frequência \\
\hline Definiu-se apenas como Pesquisa/abordagem/metodologia qualitativa & 13 \\
\hline Pesquisa-ação & 05 \\
\hline Estudo de caso & 05 \\
\hline Não definiu a metodologia empregada & 04 \\
\hline De base etnográfica & 03 \\
\hline Estudo exploratório-descritivo/pesquisa exploratório-descritiva & 02 \\
\hline Reading Recovery & 01 \\
\hline \multicolumn{1}{|c|}{ Total } & 33 \\
\hline
\end{tabular}

FONTE: Elaborado pela autora a partir de dados coletados no BDTD (http://bdtd.ibict.br).

Um aspecto que merece ser mencionado é que há maior investimento dos pesquisadores em explicitar as técnicas e instrumentos, em detrimento do método.

\section{Anais de eventos nacionais: produção nas reuniões nacionais da Anped e no Cole}

A opção por consultar os anais das reuniões nacionais da Anped e do Congresso de Leitura do Brasil deveu-se a três fatores básicos: primeiro porque ambos são de abrangência nacional, o que não limitaria a coleta a uma região; segundo porque os dois eventos dispõem de espaços para discussão sobre leitura; terceiro porque, enquanto a Anped volta-se prioritariamente para a divulgação de pesquisas (em andamento ou concluídas), o Cole é mais diversificado, visto que as comunicações podem ser de pesquisa, mas também de relatos de experiências, ensaios e outras. Tal combinação possibilitou ampliar o olhar sobre a produção acadêmica divulgada em eventos da área. Não foi utilizado nenhum recurso de contagem automática devido ao fato de que, em vários títulos, a palavra "leitura" repetiu-se. Sendo assim, mesmo que no título do resumo aparecesse mais de uma vez o descritor, foi contabilizado uma única vez por título/texto. 


\section{Anais das reuniões Anped}

Embora os anais das reuniões da Associação Nacional de Pós-Graduação e Pesquisa em Educação (Anped) ${ }^{1}$ estejam disponíveis na web, não há uniformidade na organização e disponibilização dos textos, tendo em vista que os materiais foram estruturados diferenciadamente a cada evento. Entretanto, tomando como referência os trabalhos do GT10 -"Alfabetização, Leitura e Escrita" -, foi possível consultar as produções lá constantes, a partir de 2000, que correspondem à $23^{\mathrm{a}}$ Reunião Anual.

No GT 10 não foi localizado nenhum texto que contivesse o descritor “estratégia(s) de leitura(s)" no título, não obstante o termo "leitura" estivesse presente em vários deles. Embora não fosse objetivo desta pesquisa, os textos que continham o termo "leitura"também foram consultados no referido GT, mas o conteúdo não remetia à discussão de estratégias.

\section{QUADRO 6 - GT 10 - ALFABETIZAÇÃO, LEITURA E ESCRITA}

\begin{tabular}{|c|c|c|c|}
\hline Reunião & Local/Ano & $\begin{array}{l}\text { Descritor } \\
\text { "Leitura" }\end{array}$ & $\begin{array}{c}\text { Descritor "Estratégias } \\
\text { de leituras" }\end{array}$ \\
\hline $23^{\mathrm{a}}$ & Caxambu - MG - set./2000 & 04 & 0 \\
\hline $24^{\mathrm{a}}$ & Caxambu - MG - out./2001 & 03 & 0 \\
\hline $25^{\mathrm{a}}$ & Caxambu - MG - out./2002 & 02 & 0 \\
\hline $26^{\mathrm{a}}$ & Poços de Caldas - MG - out./2003 & 02 & 0 \\
\hline $27^{\mathrm{a}}$ & Caxambu $-\mathrm{MG}-$ nov./2004 & 05 & 0 \\
\hline $28^{\mathrm{a}}$ & Caxambu - MG - out./2005 & 07 & 0 \\
\hline $29^{\mathrm{a}}$ & Caxambu - MG - out./2006 & 03 & 0 \\
\hline $30^{\mathrm{a}}$ & Caxambu - MG - out./2007 & 02 & 0 \\
\hline $31^{\mathrm{a}}$ & Caxambu - MG - out./2008 & 05 & 0 \\
\hline $32^{\mathrm{a}}$ & Caxambu - MG - out./2009 & 04 & 0 \\
\hline $33^{\mathrm{a}}$ & Caxambu - MG - out./2010 & --- & --- \\
\hline $34^{\mathrm{a}}$ & Natal $-\mathrm{RN}-$ out./2011 & 05 & 0 \\
\hline $35^{\mathrm{a}}$ & Porto de Galinhas - PE - out./2012 & 02 & 0 \\
\hline $36^{\mathrm{a}}$ & Goiânia - GO - out./2013 & 06 & 0 \\
\hline $37^{\mathrm{a}}$ & Florianópolis - SC - out./2015 & 08 & 0 \\
\hline $38^{\mathrm{a}}$ & São Luís do Maranhão - out./2017 & 06 & 0 \\
\hline Total & & 64 & 0 \\
\hline
\end{tabular}

FONTE: Elaborado pela autora a partir de dados disponíveis em: $<$ http://www.anped.org.br/news/ anais-das-reunioes-nacionais-da-anped-issn-2447-2808>.

1 Os anais consultados estão disponíveis em: <http://www.anped.org.br/news/anais-das-reunioes-nacionais-da-anped-issn-2447-2808>. 
Como é possível observar no Quadro 6, na $37^{\mathrm{a}}$ Reunião da Anped verificou-se o maior número de textos com o termo "leitura" no GT10. Importa explicar que não estão disponíveis os dados da $33^{\mathrm{a}}$ Reunião. Os links de acesso ${ }^{2}$ acusam: "Esta página não está funcionando", mesmo após diversas consultas utilizando diferentes provedores de internet.

\section{Anais do Congresso de Leitura do Brasil (Cole)}

Como a temática central do Cole é leitura, o que está evidenciado no nome do evento, e devido à sua abrangência, optou-se por delimitar a pesquisa às publicações no "Seminário sobre Letramento e Alfabetização" com o propósito de aproximar-se do GT 10 da Anped.

No decorrer da coleta verificou-se que os anais do $12^{\circ}$ ao $17^{\circ}$ Cole seguiram basicamente o mesmo padrão e os dados foram obtidos por meio de levantamento feito no "Seminário sobre Letramento e Alfabetização", cujos resultados constam no Quadro 7; porém houve alteração na organização do evento a partir do $18^{\circ}$ Congresso e as discussões e estruturação do material deixaram de ser por seminários. A coordenação geral do Congresso optou por linhas temáticas e os textos foram publicados em cadernos de resumos e revistas. Portanto a coleta de dados referentes ao $18^{\circ}$ até o $20^{\circ}$ Cole deu-se a partir dos cadernos de resumos. Isso tornou mais ágil e abrangente a busca, mas também alterou substancialmente o quantitativo de textos analisados ${ }^{3}$, o que se reflete no Quadro 7.

Como delimitação temporal, a coleta tomou como ponto inicial o $12^{\circ}$ evento, ocorrido em 1999, cujos anais já estavam na forma digital, até o $20^{\circ}$ Congresso, em 2016. Todos os Cole foram realizados na Universidade Estadual de Campinas, naquela mesma cidade do estado de São Paulo.

2 Dados indisponíveis no site $<$ http://33reuniao.anped.org.br/? ga=2.17619322.219293626. 1527266857-19707118.1525094995 e em < http://www.anped.org.br/reunioes-cientificas/nacional .

3 Não foi possível, nesta pesquisa, retomar os dados dos Cole anteriores e analisar todos os seminários, isso porque a disponibilidade de informações dos seminários anteriores segue outras formas de acesso e organização, o que inviabilizaria a análise dos dados em tempo hábil para esta publicação. 
QUADRO 7 - ANAIS DOS COLE

\begin{tabular}{|c|c|c|c|}
\hline Cole & Data & Descritor "Leitura" & Descritor "Estratégia de leitura" \\
\hline $12^{\mathbf{o}}$ & 1999 & 15 & 0 \\
\hline $13^{\mathbf{o}}$ & 2001 & 01 & 0 \\
\hline $14^{\mathbf{o}}$ & 2003 & 08 & 0 \\
\hline $15^{\mathbf{0}}$ & 2005 & 27 & 0 \\
\hline $16^{\mathbf{0}}$ & 2007 & 27 & 0 \\
\hline $17^{\mathbf{0}}$ & 2009 & 49 & 0 \\
\hline $18^{\mathbf{o}}$ & 2012 & 187 & 03 \\
\hline $19^{\circ}$ & 2014 & 302 & 06 \\
\hline $20^{\circ}$ & 2016 & 172 & 02 \\
\hline Total & & 788 & $\mathbf{1 1}$ \\
\hline
\end{tabular}

FONTE: Elaborado pela autora a partir dos dados disponíveis em $<$ http://alb.org.br/anais-cole/ $>$.

A partir do $17^{\circ}$ Coleque foram identificados textos com os termos "estratégia" e "leitura". Nos anais daquele evento foram localizados 49 textos com a palavra "leitura", em dois deles "estratégia/estratégico", mas nenhum se referia ao foco desta pesquisa.

A partir do $18^{\circ}$ Cole a Associação de Leitura do Brasil (ALB), responsável pela organização do Congresso, optou-se por publicar os artigos aceitos em outro formato que não mais os anais com textos completos, como já informado. Portanto os textos que compõem os anais do $18^{\circ}$ Cole foram publicados no número 58 da Revista Leitura: Teoria \& Prática, com um suplemento com artigos aprovados para apresentação no evento ${ }^{4}$, caso os autores fizessem essa opção e encaminhassem o texto completo para a publicação, e também o Caderno de Resumos $^{5}$, mas com outra organização, não mais por Seminários.

Em 2011, durante o evento preparatório desta edição do congresso, os membros da diretoria e do Colegiado de Representantes da Associação de Leitura do Brasil concordaram em alterar o formato de anais para que a submissão dos trabalhos ao $18^{\circ}$ Cole viesse a representar também a submissão de textos completos à publicação em uma das revistas editadas pela ALB: a revista impressa Leitura: Teoria \& Prática e a revista on-line Linha Mestra. Além disso, a fim de fortalecer os laços entre a entidade,

4 Leitura: Teoria \& Prática (Suplemento), n.58, jun.2012. Disponível em: <http://alb.org. br/arquivo-morto/edicoes_anteriores/anais18/pdf/ltp_58_suplemento_18cole_01_401.pdf.>.Acesso em: 01 maio 2018.

5 Disponível em: <http://alb.org.br/wp-content/uploads/2016/11/18-cole-caderno-de-resumos-final-1.pdf.>. Acesso em: 01 maio 2018. 
os nossos parceiros e os participantes, a submissão se daria mediante associação à entidade (COLE, 2012, p. 09).

Para o $18^{\circ}$ Cole foram aprovados 615 trabalhos, dentre os quais 187 traziam no título o termo "leitura(s)" - lembrando que a lógica de organização dos materiais e apresentações não eram mais por seminários, como até então, mas sim por linhas temáticas. Portanto foi feito o levantamento de dados observando todos os resumos constantes no Caderno, para posterior leitura do texto integral, quando e se pertinente. Isso explica, ao menos em parte, porque a quantidade de textos com a palavra "leitura" salta de 49 (2009) para 187 (2012).

Dentre os 615 textos, quatro continham o termo "estratégia" no título, mas não se referiam a "estratégias de leitura", eram sobre estratégias linguísticas, familiares e de intervenção didática. Com o descritor "estratégia(s) de leitura" no título foram localizados três textos, que são:

1. Estratégias de leitura e contação de histórias na educação infantil, de Daniela Gaspar Pedrazzoli Bagnasco e Ana Lúcia Guedes-Pinto.

2. Estratégias de leitura: a antecipação e a compreensão leitora, de Miriam Raquel Piazzi Machado.

3. Leitura, literatura infantil e estratégias de leitura: concepções e práticas, de Vanessa Bataus.

Os trabalhos aprovados no $19^{\circ}$ Cole, por sua vez, foram publicados na Revista Linha Mestra - Edição Especial $-19^{\circ}$ Congresso de Leitura do Brasil $^{6}$. A revista divide-se em partes: a primeira com o expediente do periódico, a apresentação, o editorial e artigos apresentados em mesas redondas durante o congresso; outra, com os trabalhos das seções de comunicação, dividida em 16 subpartes e organizada por nome de autor reunindo 706 textos de 1.009 conferencistas. Aqui também é suprimida a estruturação por seminários, como vinha sendo feito até então e também há o caderno de resumos ${ }^{7}$.

No Caderno de Resumos do $19^{\circ}$ Cole constam 833 trabalhos aprovados, dentre os quais 302 apresentavam a palavra "leitura(s)" no título (foi contado o título, não contabilizando se ele possuía várias vezes a mesma palavra). Desse total, seis traziam em seus títulos o descritor "estratégia de leitura", a saber:

6 Revista Linha Mestra - Ano VIII. n. 24 (jan./jul. 2014). Disponível em: < https://linhamestra24.wordpress.com/artigos/>. Acesso em: 01 maio 2018.

7 Disponível em: < http://alb.org.br/wp-content/uploads/2015/11/19-cole-caderno_resumos. pdf. $>$. Acesso em: 01 maio 2018. 
1. Uma proposta de ensino de estratégia de leitura com literatura infantil, de Joice Ribeiro Machado da Silva.

2. Estratégias de leitura e o ensino do ato de ler, de Silvana Paulina de Souza.

3. Quais as estratégias de leitura utilizadas pelas crianças em interação com histórias em quadrinhos?, de Ariane Rodrigues Gomes Leite e Maiara Ferreira de Souza.

4. Estratégias de leitura na formação continuada de professores alfabetizadores, Gislene Aparecida da Silva Barbosa.

5. Definição de estratégias de leitura com base no perfil do leitor em formação, de Veruska Ribeiro Machado; Rosa Amélia Pereira da Silva.

6. Literatura infantil e estratégias de leitura: o professor como mediador de leitura e a formação de leitores, de Vanessa Bataus.

Registre-se que também foram identificados no Caderno de Atividades e Resumos do $19^{\circ}$ Cole quatro textos que traziam o termo "estratégia" no título, mas se referiam a "estratégias da governamentalidade", de "motivação" e "metodológica"; portanto não foram aqui analisados, ou não apresentavam a locução estudada.

Como no evento anterior, os textos dos participantes do $20^{\circ}$ Cole foram publicados na Revista Linha Mestra ${ }^{8}$ e em caderno de resumos ${ }^{9}$. Essa edição especial (ano X, n. 30) contém 291 artigos referentes a comunicações orais e mesas-redondas, totalizando 461 trabalhos aprovados entre mesas e seções de comunicação.

No Caderno de Atividades e Resumos do $20^{\circ}$ Congresso foram identificados 172 textos com o termo leitura no título. Desse total, sete continham a palavra "estratégia(s)" no título, mas não se referiam à "estratégia de leitura", abordavam: estratégia de interação social, de formação, de ensino, metodológicas, de aprendizagem e de sobrevivência. No material analisado foram localizados dois resumos que apresentavam o descritor "estratégia de leitura(s)" no título: 1. Nas dobras da memória e da experiência: o conhecimento prévio como estratégia de compreensão leitora a partir da literatura para crianças, de Marta Campos de Quadros e Renata Junqueira de Souza.

2. O ensino das estratégias de leitura pelo viés da literatura para crianças: diálogos possíveis e imprescindiveis, de Neyse Siqueira Cardoso e Gildene Lima de Souza Fernandes.

8 Revista Linha Mestra - Ano X. n. 30 (set./dez.2016). Disponível em:<https://linhamestra30.wordpress.com/artigos/>. Acesso em: 01 mai. 2018.

9 Disponível em: $<$ http://alb.org.br/wp-content/uploads/2015/11/20_cole_caderno_resumos_site.pdf.>. Acesso em: 01 mai. 2018. 
Importante destacar que um dos fatores relacionados à diminuição geral de textos aprovados no $20^{\circ}$ Cole foi a redução de vagas para participação no Congresso, o que não se verificava nas edições anteriores.

Quanto ao referencial que subsidiou a discussão sobre "estratégias de leitura" nos textos analisados referentes aos Congressos de Leitura, foi possível observar a confluência de autores, se comparados com as teses e dissertações (Quadro 8).

QUADRO 8 - PRINCIPAIS OBRAS QUE FUNDAMENTAM AS DISCUSSÕES SOBRE "ESTRATÉGIAS DE LEITURA" NOS TEXTOS PUBLICADOS EM EVENTOS

\begin{tabular}{|l|c|}
\hline \multicolumn{1}{|c|}{ Autor/obra } & Freq. \\
\hline $\begin{array}{l}\text { GIROTTO, Cyntia Graziella Guizelim Simões; SOUZA, Renata Junqueira de. } \\
\text { Estratégias de leitura: para ensinar alunos a compreender o que leem }\end{array}$ & 04 \\
\hline SOLÉ, I. Estratégias de Leitura & 03 \\
\hline $\begin{array}{l}\text { HARVEY, Stephanie; GOUDVIS, Anne. Strategies that work: teaching } \\
\text { comprehension for understanding and engagement }\end{array}$ & 02 \\
\hline KLEIMAN, Angela. Leitura: ensino e pesquisa & 01 \\
\hline PRESSLEY, M. Reading instruction that works: the case for balanced teaching & 01 \\
\hline
\end{tabular}

FONTE: Elaborado pela autora a partir dos dados disponíveis em <http://alb.org.br/anais-cole/ $>$.

No que concerne à questão da metodologia da pesquisa, verificou-se nos 11 textos que constam nas publicações do Cole imprecisão ou mesmo omissão da discussão metodológica, visto que em sete textos não há menção à metodologia empregada. Em outros três as autoras indicam a pesquisa-ação como opção, e em um consta que a base metodológica foi Experimento Formativo.

\section{Artigos em periódicos na biblioteca eletrônica SciELO}

Devido à abundância de periódicos disponíveis na internet, optou-se por consultar a base Scientific Electronic Library Online (SciELO), por se tratar de uma biblioteca eletrônica que abrange uma coleção seleta de periódicos científicos brasileiro. Sobre a SciELO, Chinchilla-Rodríguez e Moya-Anegón (2011) afirmam que 
A Rede SciELO é a maior provedora de periódicos indexados pelo Diretório de Periódicos de Acesso Aberto (Directoryof Open Access Journals - DOAJ). A maioria dos periódicos latino-americanos indexados pela Web of Science e Scopus é de acesso aberto, sendo a maior parte deles periódicos do SciELO. Nenhuma outra região do mundo tem esse nível de adoção de periódicos de acesso aberto indexados internacionalmente (Apud PACKER; MENEGHINI, 2014, p. 16).

Dessa forma, utilizando o descritor "estratégia de leitura" foram localizados dois artigos:

1. Estratégias de leitura e competência leitora: contribuições para a prática de ensino em História, de Vitória Rodrigues e Silva. O texto consiste em um ensaio tendo como referência básica a obra de Solé (1998). O objetivo é "tecer algumas considerações sobre as contribuições que a metodologia de leitura apresentada por Isabel Solé pode oferecer para a prática do ensino de História." (SILVA, 2004, p. 69).

2. Programa Nacional do Livro Didático (PNLD) - Acervos Complementares: vivência das estratégias de leitura na alfabetização, de Rielda Karyna de Albuquerque e Magna Silva Cruz. O texto apresenta um relato de pesquisa que teve enfoque qualitativo e "investigou as concepções dos professores e o uso das obras do PNLD - Acervos Complementares visando ao aprendizado da leitura nas turmas de $1^{\circ}$ e $2^{\circ}$ ano do EF." (ALBUQUERQUE; CRUZ, 2015, p. 443). O referencial base para a discussão sobre "estratégias de leitura" pautou-se em Solé (1998/2012) e Kleiman (2002), incluindo Colomer e Camps, com Ensinar a ler, ensinar a compreender, e Brandão (2006), com o texto $O$ ensino da compreensão e a formação do leitor: explorando as estratégias de leitura.

\section{Considerações finais}

O propósito deste texto foi, dentro dos seus limites, apresentar um balanço da pesquisa sobre "estratégias de leitura" tomando como referência publicações constantes em três bases: teses e dissertações publicadas na BDTD, anais de dois eventos nacionais (Anped e Cole) e artigos de periódicos que constassem na SciELO, com a demarcação temporal de 2000 a 2017.

Tendo em vista a multiplicidade de textos que se voltam para o tema "leitura", a delimitação para a coleta de dados foi a presença da expressão "estratégia 
de leitura" no título da publicação. Foram desconsiderados textos nos quais as palavras "estratégia" e "leitura" não formassem uma locução.

Outro fato importante a destacar é a divulgação de dados de pesquisas realizadas em mestrados e doutorados circulando em eventos da área, o que possibilita a interlocução com outros pesquisadores, estudantes e professores das redes públicas e privadas, com trocas de conhecimentos e experiências.

\section{REFERÊNCIAS}

ALBUQUERQUE, Rielda Karyna de; CRUZ, Magna Silva. Programa Nacional do Livro Didático (PNLD) - Acervos Complementares: vivência das estratégias de leitura na alfabetização. Rev. Bras. Estud. Pedagog. [on-line], v. 96, n. 243, p. 439-456, 2015. Disponível em: <http://www.scielo.br/scielo.php?script=sci_arttext\&pid=S2176$-66812015000200439 \& \operatorname{lng}=\mathrm{en} \& n r m=$ iso $>$. Acesso em: 30 abr. 2018.

BAGNASCO, Daniela Gaspar Pedrazzoli; GUEDES-PINTO, Ana Lúcia. Estratégias de leitura e contação de histórias na educação infantil. In: Cole. Congresso de Leitura do Brasil. Caderno de Resumos. $18^{\circ}$ Cole. Coordenação geral: Antonio Carlos Amorim et al. Campinas, SP: FE/UNICAMP; ALB, 2012, p. 144-145. Disponível em: <http://alb. org.br/wp-content/uploads/2016/11/18-cole-caderno-de-resumos-final-1.pdf $>$. Acesso em: 01 maio 2018.

BARBOSA, Gislene Aparecida da Silva. Estratégias de leitura na formação continuada de professores alfabetizadores. In: Cole. Congresso de Leitura do Brasil. Caderno de Atividades e Resumos. $19^{\circ}$ Cole. Coordenação geral: Ana Lúcia Horta Nogueira; Davina Marques. Campinas, SP: FE/UNICAMP; ALB, 2014, p. 229-230. Disponível em: $<$ http://alb.org.br/wp-content/uploads/2015/11/19-cole-caderno_resumos.pdf $>$. Acesso em: 01 maio 2018.

BATAUS, Vanessa. Leitura, literatura infantil e estratégias de leitura: concepções e práticas. In: Cole. Congresso de Leitura do Brasil. Caderno de Resumos. $18^{\circ}$ Cole. Coordenação geral: Antonio Carlos Amorim et al. Campinas, SP: FE/UNICAMP; ALB, 2012, p. 340-341. Disponível em: <http://alb.org.br/wp-content/uploads/2016/11/18-cole-caderno-de-resumos-final-1.pdf>. Acesso em: 01 maio 2018.

BATAUS, Vanessa. Literatura infantil e estratégias de leitura: o professor como mediador de leitura e a formação de leitores. In: Cole. Congresso de Leitura do Brasil. Caderno de Atividades e Resumos. $19^{\circ}$ Cole. Coordenação geral: Ana Lúcia Horta Nogueira; Davina Marques. Campinas, SP: FE/UNICAMP; ALB, 2014, p. 372. Disponível em: $<\mathrm{http} / / /$ alb.org.br/wp-content/uploads/2015/11/19-cole-caderno_resumos.pdf $>$. Acesso em: 01 maio 2018. 
BRANDÃO, Ana Carolina Perrusi. O ensino da compreensão e a formação do leitor: explorando as estratégias de leitura. In: BARBOSA, Maria Lúcia Ferreira de Figueiredo; SOUZA, Ivane Pedrosa de. Práticas de leitura no ensino fundamental. Belo Horizonte: Autêntica, 2006, p. 59-75. Disponível em: <http://coordenacaoescolagestores.mec.gov. $\mathrm{br} / \mathrm{ufsc} /$ file.php/1/coord_ped/sala_12/arquivos/Praticas_de_leitura_anexo-2.pdf $>$. Acesso em: 30 abr. 2018.

CARDOSO, Neyse Siqueira; FERNANDES, Gildene Lima de Souza. O ensino das estratégias de leitura pelo viés da literatura para crianças: diálogos possíveis e imprescindíveis. In: Cole. Congresso de Leitura do Brasil. Caderno de Atividades e Resumos. $20^{\circ}$ Cole. Coordenação geral: Adriana Lia Friszman de Laplane; Davina Marques; Marcus Pereira Novaes. Campinas, SP: FE/UNICAMP; ALB, 2016, p. 88. Disponível em: $<$ http://alb.org.br/wp-content/uploads/2015/11/20_cole_caderno_resumos_site.pdf $>$. Acesso em: 01 maio 2018.

COLE. Congresso de Leitura do Brasil. Caderno de Resumos. $18^{\circ}$ Cole. Coordenação geral: Antonio Carlos Amorim et al. Campinas, SP: FE/UNICAMP; ALB, 2012. Disponível em: $<$ http://alb.org.br/wp-content/uploads/2016/11/18-cole-caderno-de-resumos-final-1. pdf $>$. Acesso em: 01 maio 2018.

COLE. Congresso de Leitura do Brasil. Caderno de Atividades e Resumos. $19^{\circ}$ Cole. Coordenação geral: Ana Lúcia Horta Nogueira; Davina Marques. Campinas, SP: FE/UNICAMP; ALB, 2014. Disponível em: <http://alb.org.br/wp-content/uploads/2015/11/19-cole-caderno_resumos.pdf $>$. Acesso em: 01 maio 2018.

COLE. Congresso de Leitura do Brasil. Caderno de Atividades e Resumos. $20^{\circ}$ Cole. Coordenação geral: Adriana Lia Friszman de Laplane; Davina Marques; Marcus Pereira Novaes. Campinas, SP: FE/UNICAMP; ALB, 2016. Disponível em: <http://alb.org. br/wp-content/uploads/2015/11/20_cole_caderno_resumos_site.pdf $>$. Acesso em: 01 maio 2018.

COLOMER, Teresa; CAMPS, Anna. Ensinar a ler, ensinar a compreender. Porto Alegre: Artmed, 2002.

FERREIRA, Norma Sandra de Almeida. As pesquisas denominadas "estado da arte". Educação \& Sociedade, ano XXIII, n. 79, p. 257-272, ago. 2002, Disponível em <http:// www.scielo.br/pdf/es/v23n79/10857.pdf>. Acesso em: 16 abr. 2018.

KATO, Mary. O aprendizado da leitura. 4. ed. São Paulo: Martins Fontes, 1995.

KLEIMAN, Angela. Oficina de Leitura: Teoria e Prática. 9. ed. Campinas, SP: Pontes. 2002.

KOCH, Ingedore; ELIAS, Vanda Maria. Ler e compreender: os sentidos do texto. 2. ed. São Paulo: Contexto, 2007.

LEITE, Ariane Rodrigues Gomes; SOUZA, Maiara Ferreira de. Quais as estratégias de leitura utilizadas pelas crianças em interação com histórias em quadrinhos? In: Cole. Congresso de Leitura do Brasil. Caderno de Atividades e Resumos. $19^{\circ}$ Cole. Coordena- 
ção geral: Ana Lúcia Horta Nogueira; Davina Marques. Campinas, SP: FE/UNICAMP; ALB, 2014, p. 149. Disponível em: <http://alb.org.br/wp-content/uploads/2015/11/19-cole-caderno_resumos.pdf $>$. Acesso em: 01 maio 2018.

MACHADO, Miriam Raquel Piazzi. Estratégias de leitura: a antecipação e a compreensão leitora. In: Cole. Congresso de Leitura do Brasil. Caderno de Resumos. $18^{\circ}$ Cole. Coordenação geral: Antonio Carlos Amorim et al. Campinas, SP: FE/UNICAMP; ALB, 2012, p. 337. Disponível em: <http://alb.org.br/wp-content/uploads/2016/11/18-cole-caderno-de-resumos-final-1.pdf $>$. Acesso em: 01 maio 2018.

MACHADO, Veruska Ribeiro; SILVA, Rosa Amélia Pereira da. Definição de estratégias de leitura com base no perfil do leitor em formação. In: Cole. Congresso de Leitura do Brasil. Caderno de Atividades e Resumos. $19^{\circ}$ Cole. Coordenação geral: Ana Lúcia Horta Nogueira; Davina Marques. Campinas, SP: FE/UNICAMP; ALB, 2014, p. 360-361. Disponível em: <http://alb.org.br/wp-content/uploads/2015/11/19-cole-caderno_resumos. pdf>. Acesso em: 01 maio 2018.

PACKER, Abel L.; MENEGHINI, Rogério. O SciELO aos 15 anos: raison d'être, avanços e desafios para o futuro. In: PACKER, Abel L. et al. (Org.). SciELO - 15 anos de Acesso Aberto [livro eletrônico]: um estudo analítico sobre Acesso Aberto e comunicação científica. Paris: UNESCO, 2014. p. 15-28. Disponível em: <http://unesdoc.unesco.org/ images/0022/002272/227291por.pdf>. Acesso em: 07 maio 2018.

QUADROS, Marta Campos de; Souza, Renata Junqueira de. Nas dobras da memória e da experiência: o conhecimento prévio como estratégia de compreensão leitora a partir da literatura para crianças. In: Cole. Congresso de Leitura do Brasil. Caderno de Atividades e Resumos. $20^{\circ}$ Cole. Coordenação geral: Adriana Lia Friszman de Laplane; Davina Marques; Marcus Pereira Novaes. Campinas, SP: FE/UNICAMP; ALB, 2016, p. 80. Disponível em: <http://alb.org.br/wp-content/uploads/2015/11/20_cole_caderno_resumos_site.pdf>.Acesso em: 01 maio 2018.

ROMANOWSKI, Joana Paulin; ENS, Romilda Teodora. As pesquisas denominadas do tipo "estado da arte" em educação. Diálogo Educacional revista [online], v. 6, n. 19, p. 37-50, set./dez. 2006. Disponível em: <http://www.redalyc.org/articulo. oa? $\mathrm{id}=189116275004>$. ISSN 1518-3483. Acesso em: 07 maio 2015.

SILVA, Joice Ribeiro Machado da. Uma proposta de ensino de estratégia de leitura com literatura infantil. In: Cole. Congresso de Leitura do Brasil. Caderno de Atividades e Resumos. $19^{\circ}$ Cole. Coordenação geral: Ana Lúcia Horta Nogueira; Davina Marques. Campinas, SP: FE/UNICAMP; ALB, 2014, p. 135-136. Disponível em: < http://alb.org.br/ wp-content/uploads/2015/11/19-cole-caderno_resumos.pdf $>$. Acesso em: 01 maio 2018.

SILVA, Vitória Rodrigues e. Estratégias de leitura e competência leitora: contribuições para a prática de ensino em História. História [online], v. 23, n. 1-2, p. 69-83, 2004. Disponível em: <http://www.scielo.br/pdf/his/v23n1-2/a05v2312.pdf>. Acesso em: 30 abr. 2018 .

SOLÉ, Isabel. Estratégias de leitura. 6. ed. reimp. Porto Alegre: Artmed, 2012. 
SOUZA, Silvana Paulina de. Estratégias de leitura e o ensino do ato de ler. In: Cole. Congresso de Leitura do Brasil. Caderno de Atividades e Resumos. $19^{\circ}$ Cole. Coordenação geral: Ana Lúcia Horta Nogueira; Davina Marques. Campinas, SP: FE/UNICAMP; ALB, 2014, p. 139-140. Disponível em: <http://alb.org.br/wp-content/uploads/2015/11/19-cole-caderno_resumos.pdf $>$. Acesso em: 01 maio 2018.

Texto recebido em 08 de junho de 2018. Texto aprovado em 08 de agosto de 2018. 